\title{
Fanfictions: leitura e escrita na cibercultura
}

\author{
Fanfiction: lectura y escritura en la cibercultura
}

Fanfiction: reading and writing in Cyberculture

\author{
Monica do Amparo Silva ${ }^{1}$ \\ Mariza Inês da Silva Pinheiro ${ }^{2}$ \\ Lúcia Helena Vitalli Range ${ }^{3}$
}

\begin{abstract}
Resumo
A condição letrada é um fenômeno de natureza complexa e multifacetada. Organiza-se em torno de um conjunto de gestos e comportamentos diversificados, de competências e habilidades heterogêneas, de objetos histórica e socialmente diferenciados; é construída por meio de um conjunto de práticas e de uma rede de instituições, agentes e materiais; responsável por grandes divisões no interior da sociedade e um dos fatores que poderiam transformá-la. O ingresso na cultura escrita por sociedades ocidentais já foi considerado uma das principais evoluções da era moderna. Dominar a escrita era também a produzir. Contemporaneamente, uma sociedade civilizada chega a exigir de seus membros o domínio e utilização da leitura de variados suportes em variadas formas (pois cada suporte acaba por desenvolver um modo de leitura peculiar). Pode-se, pois, inferir que o ato de ler é um ato de esforço e concentração que também exige reflexão. Dessa forma, a leitura assume o papel de um processo de disciplina intelectual, exigindo uma posição crítica daquele que é o leitor. Os ciberjovens não só consomem a leitura e toda produção midiática. Eles interagem com essa produção e realizam uma recriação cultural com identidade e público próprios denominada fanfiction cuja escrita pode ser divulgada em diferentes plataformas do ciberespaço sob diversos gêneros textuais. Este artigo é resultado da reflexão baseada na observação de um app que permite a escrita/ leitura e a divulgação dessa produção.
\end{abstract}

Palavras-chave: cibercultura; escrita; fanfiction; leitura

\section{Resumen}

La condición es un fenómeno complejo y multifacético de naturaleza sabe leer y escribir. Organizada alrededor de un conjunto de gestos y comportamientos diversos, Aptitudes y habilidades, objetos históricos y heterogéneo socialmente diferenciados; Se construye mediante un conjunto de prácticas y de una red de instituciones, agentes y materiales; Sería la base de las divisiones dentro de la sociedad y uno de los factores que podrían

\footnotetext{
${ }^{1}$ (Mestre em Ciência da Informação; Escola de Ciência da Informação da Universidade Federal de Minas Gerais - ECl /UFMG; Belo Horizonte, Minas Gerais, Brasil; Universidade Federal de Mato Grosso - UFMT / Rondonópolis, Mato Grosso, Brasil; Doutoranda do Programa de Pós-graduação em Ciências Sociais; Pontifícia Universidade Católica de São Paulo - PUCSP; São Paulo, São Paulo, Brasil; monicaamparosilva@gmail.com). Trabalho apresentado no I Seminário Latino-Americano de Estudos em Cultura - SEMLACult, Foz do Iguaçu/PR, Brasil, 2017.
}

2 (Doutora em Documentação; Universidade Carlos III; Madrid, Espanha; Universidade Federal de Mato Grosso - UFMT / Rondonópolis, Mato Grosso, Brasil; mariza-inez@hotmail.com). Trabalho apresentado no I Seminário Latino-Americano de Estudos em Cultura - SEMLACult, Foz do Iguaçu/PR, Brasil, 2017.

${ }^{3}$ (Pós-Doutorado em Ciências Sociais, Infância e Juventude; Universidade de Manizales, - Clacso; Colômbia; Colef / México; Pontifícia Universidade Católica de São Paulo - PUCSP; São Paulo, São Paulo, Brasil; lurangel@pucsp.br). Trabalho apresentado no I Seminário Latino-Americano de Estudos em Cultura SEMLACult, Foz do Iguaçu/PR, Brasil, 2017. 
hacerlo. El billete en la cultura escrita por las sociedades occidentales ha sido considerado uno de los principales acontecimientos de la era moderna. Amo la escritura era también producirlo. Al mismo tiempo, una sociedad civilizada viene a exigir de sus miembros del dominio y uso de diversos apoyos en varias formas (porque cada soporte eventualmente desarrollar un modo de lectura peculiar). Por lo tanto, uno puede deducir que el acto de lectura es un acto de esfuerzo y concentración que requiere reflexión. De esta manera, la lectura asume el papel de un proceso de disciplina intelectual, exige una visión crítica del lector. Los ciberadolescentes consumir no sólo la lectura y toda la producción de los medios de comunicación. Interactuar con tal producción y realice una identidad cultural y público llamado fanfiction cuya escritura puede difundirse en diferentes plataformas de ciberespacio en varios géneros de texto. Este artículo es el resultado de la reflexión basada en la observación de una aplicación que permite la lecturalescritura y la difusión de esta producción.

Palabras clave: CIBERCULTURA; la escritura; Fanfiction; lectura

\begin{abstract}
The literate condition is a phenomenon of complex and multifaceted nature. It is organized around a set of diversified gestures and behaviors, heterogeneous skills and abilities, historical and socially differentiated objects; Is built through a set of practices and a network of institutions, agents and materials; Would be the basis of divisions within society and one of the factors that could transform it. The entry into the culture written by western societies was already considered one of the main evolutions of the modern era. Mastering writing was also to produce. At the same time, a civilized society even demands from its members the mastery and use of the reading of various supports in various forms (since each medium develops a peculiar reading mode). One can therefore infer that the act of reading is an act of effort and concentration that also requires reflection. In this way, reading assumes the role of a process of intellectual discipline, demanding a critical position from the reader. Not only do cyber-girls consume reading and all media production. They interact with this production and perform a cultural re-creation with their own identity and public called fanfiction whose writing can be disseminated in different platforms of cyberspace under different textual genres. This article is the result of reflection based on the observation of an app that allows the writing / reading and the dissemination of this production.
\end{abstract}

Keywords: Cyberculture; Writing; Fanfiction; reading

\title{
1. Introdução
}

A condição letrada é um fenômeno de natureza complexa e multifacetada. Organiza-se em torno de um conjunto de gestos e comportamentos diversificados, de competências e habilidades heterogêneas, de objetos histórica e socialmente diferenciados; é construída por meio de um conjunto de práticas e de uma rede de instituições, agentes e materiais; seria a base de divisões no interior da sociedade e um dos fatores que poderiam transformá-la.

O ingresso na cultura escrita por sociedades ocidentais já foi considerado uma das principais evoluções da era moderna. Dominar a escrita era também a produzir.

Contemporaneamente, uma sociedade civilizada chega a exigir de seus membros o domínio e utilização da leitura de variados suportes em variadas formas (pois cada suporte acaba por desenvolver um modo de leitura peculiar).

Pode-se, pois, inferir que o ato de ler é um ato de esforço e concentração que também exige reflexão. 
Dessa forma, a leitura assume o papel de um processo de disciplina intelectual, exigindo uma posição crítica daquele que é o leitor.

Os ciberjovens não só consomem a leitura e toda produção midiática. Eles interagem com essa produção e realizam uma recriação cultural com identidade e público próprios. Uma escrita que é símbolo de sua geração, condição e posição diante da sociedade: as fanfictions.

Esta por sua vez pode ser divulgada em diferentes plataformas do ciberespaço, é líquida e pode ser encontrada sob diversos gêneros textuais. Este artigo é resultado da observação de algumas manifestações de leitura/escrita que permite a escrita/ leitura e a divulgação dessa produção, mas acima de tudo propõe-se a provocações. Os jovens leem? Se não, como são capazes de produzir escrita? Que leitura é esperada dos ciberjovens numa realidade líquida?

Não é proposta uma exaustiva descrição do ambiente em que a fanfiction é produzida. Serão tecidas algumas noções básicas, mas fundamentais a questionamentos pontuais sobre leitura/escrita em novas plataformas bem como a necessidade de novos olhares, de novo e sempre...

\section{Contextualização}

A sociedade contemporânea, chamada sociedade da informação ou do conhecimento, apresenta novas possibilidades de informação, produção, análise, transferência e interação com o conhecimento que fascinam e envolvem os olhos humanos. $\mathrm{O}$ consumo da cibercultura é uma realidade. E a apresentação da mídia sempre uma nova surpresa, um novo espetáculo.

Os hábitos dos indivíduos mudaram no momento em que a internet quebrou a barreira geográfica e imprimiu velocidade de acesso às informações, isto é, o chamado tempo real. Nesse contexto, com o advento da web 2.0, surgem novas ferramentas que promovem o convívio social e o diálogo online entre os usuários e são adotadas rapidamente, dessa maneira, por meio de mensagens diretas, posts compartilhados, fóruns de discussão, blogs e mini blogs (como o Twitter), se estrutura uma rede de sociabilidade que imprime nova dinâmica aos relacionamentos e modifica o desenvolvimento sobre o processo de geração e disseminação da informação.

As pessoas passam a compartilhar ideias, conhecimentos, notícias, links, informações numa potência impossível de ser conduzida fora da rede. A organização é estruturada por meio de vínculos entre pessoas/grupos com interesses e preocupações comuns. E essa rede cresce em todo o globo. A escola já não mais é o centro do saber. Este se faz cotidianamente 
nos mais diversificados espaços e plataformas. Seja na vida real, seja por vídeos no YouTube, por postagens e comentários no Facebook etc.

O fenômeno da globalização patrocinado pelo modelo de sociedade caracterizada por avanços técnicos científicos informacionais (SANTOS, 2010), somado ao moderno sistema de transportes ágeis e dinâmicos, maior poder de compra cedido pela lógica do capitalismo, além das facilidades de comunicação, torna esse fenômeno abrangente. É uma integração mundial não só econômica, mas com uma dimensão política, social e cultural.

A Globalização do mundo expressa um novo ciclo de expansão do capitalismo, como modo de produção e processo civilizatório de alcance mundial. Um processo de amplas proporções envolvendo nações e nacionalidades, regimes políticos e projetos nacionais, grupos e classes sociais, economias e sociedades, culturas e civilizações. Assinala a emergência da sociedade global, como uma totalidade abrangente, complexa e contraditória (IANNI, 1997).

Essa Era informacional traz uma integração positiva do conhecimento, na qual é possível estudar e conhecer hábitos culturais (músicas, vestimentas, alimentações, línguas, técnicas) de todo o mundo, ter acesso a obras literárias e científicas produzidas em qualquer lugar, e não só receber informações, como também transmitir. No entanto, o acesso a pessoas e conhecimentos diversos pode influenciar negativamente nossos hábitos. Os padrões globais apresentados vêm sendo seguidos, deixando de lado os padrões locais, e acabam por promover uma descaracterização dos hábitos culturais em detrimento dos modelos globais aderidos (BAUMAN,1999; CANCLINI, 2005).

$\mathrm{O}$ enfraquecimento da cidadania estaria nesse sentido diretamente relacionado com a crise de identidade que, por sua vez, está relacionada, entre outras coisas, com a globalização do mercado e das comunicações e a oferta de consumo.

Passa-se, assim, do amplo espaço da globalização meramente conceitual para a globalização que influencia na subjetividade dos indivíduos, tanto em suas relações políticas, coletivas, quanto individuais.

Mediante as profundas transformações suscitadas pela globalização, Canclini (2005) elenca cinco pontos daquilo que ele chama de novo cenário sociocultural. São eles:

a) Um redimensionamento das instituições e dos circuitos de exercícios do público; b) A reformulação dos padrões de assentamento e convivência urbanos; c) A reelaboração do "próprio", devido ao predomínio dos bens e mensagens provenientes de uma economia e uma cultura globalizadas sobre aqueles gerados na cidade e na nação a que se pertence; d) A consequente redefinição do senso de pertencimento e identidade, organizado cada vez menos 
por lealdades locais ou nacionais e mais pela participação em comunidades transnacionais ou desterritorializadas de consumidores; e) A passagem do cidadão como representante de uma opinião pública ao cidadão interessado em desfrutar de uma certa qualidade de vida.

Uma das manifestações desta mudança é que as formas argumentativas e críticas de participação dão lugar à fruição de espetáculos nos meios eletrônicos, em que a narração ou simples acumulação de anedotas prevalece sobre a reflexão em torno dos problemas, e a exibição fugaz dos acontecimentos sobre usa abordagem estrutural e prolongada.

A mídia, dentro dessa perspectiva, aparece como aparato facilitador e assume o papel de disseminar os objetivos desse novo paradigma de sociedade. São os meios através dos quais as informações em todas as suas dimensões são transmitidas e perigosamente controladas por um grupo a partir de seus interesses.

A cultura local expressa a identidade de um povo e revela sua história, por vezes comprometida pela globalização, pois já não se percebe essa identidade cultural tão nítida, mas assumem características globais híbridas. Essa nova realidade acontece, graças ao advento dos novos aparatos tecnológicos e informacionais que possibilitam a instantaneidade das informações, ações e acontecimentos que invadem e criam novos comportamentos e territórios.

Junto do fenômeno da globalização, e reforçando este ainda mais, aparece a cibercultura.

O termo cibercultura é concebido pela junção das palavras cibernética e cultura, “ciber" que seria o diminutivo de cibernética proposto por Pierre Lévy (2009), sendo esta uma ciência que surgiu a partir da utilização da rede de computadores através da comunicação virtual. Assim, pode dizer que é também o estudo de diversos fenômenos sociais interligados à internet, como os jogos sociais, mídias sociais, mensagens de texto, os quais inserem questões voltadas para a formação de rede, identidade e privacidade. Segundo Lévy (2009, p.11):

\footnotetext{
Pensar em cibercultura, consiste apenas em reconhecer dois fatos. Em primeiro lugar, que o crescimento do ciberespaço resulta de um movimento internacional de jovens ávidos para experimentar, coletivamente, formas de comunicação diferentes daquelas que as mídias clássicas nos propõem. Em segundo lugar, que estamos vivendo a abertura de um novo espaço de comunicação, e cabe apenas a nós explorar as potencialidades mais positivas deste espaço nos planos econômicos, políticos, cultura e humano.
}

Conforme o autor, o hábito das tecnologias está diretamente interligado aos jovens, que neste sentido, o crescimento do ciberespaço contribui de forma significativa para as diversas formas de comunicação a serem exploradas pelos os jovens, coletivamente, assim 
possibilitando-os a veem novas aberturas acerca dos meios de comunicações, diferentes das tradicionais.

O termo [ciberespaço] especifica não apenas a infraestrutura material da comunicação digital, mas também o universo oceânico de informação que ela abriga, assim como os seres humanos que navegam e alimentam esse universo. Quanto ao neologismo 'cibercultura', especifica aqui o conjunto de técnicas (materiais e intelectuais), de práticas, de atitudes, de modos de pensamento e de valores que se desenvolvem juntamente com o crescimento do ciberespaço (LÉVY, 1999, p. 17)

Com isso, é possível compreender que a sociedade está imersa a passar por um processo de universalização da cibercultura, na medida em que são entrelaçadas aos meios de comunicação com os diversos conhecimentos oferecidos por ela.

Se, a virtualização é uma das tendências que acompanha o crescimento do ciberespaço. Para Lévy (op. cit), o virtual não se opõe ao real, nem ao material. Ainda que não esteja fixo em nenhuma coordenada de tempo e espaço, o virtual existe, ele é real, mas está desterritorializado.

Na verdade, ele ocupa apenas um espaço físico menor: o computador, um instrumento, uma ferramenta de produção de sons, textos e imagens, é também um operador de virtualização.

A existência passa a ser processada em dois âmbitos diferentes: o ambiente real, o físico, e o virtual - que também é real. A reconfiguração do espaço e do tempo leva à negação da materialidade numa vivência virtual, onde o físico passa a não ser mais necessário.

O que é presente é sempre um fluxo imagético-informacional, uma interface que tecnologicamente converte o tempo em espaço social e temporaliza o espaço geográfico. $\mathrm{O}$ campo percepcional se dirige totalmente para isso, na medida em que a consciência se concentra na tela.

Segundo Bauman (2009, p. 7 - 8):

A "vida líquida" e a "modernidade líquida" estão intimamente ligadas. A "vida líquida" é uma forma de vida que tende a ser levada à frente numa sociedade líquido-moderna. "Líquido-moderna" é uma sociedade em que as condições sob as quais agem seus membros mudam num tempo mais curto do que aquele necessário para a consolidação, em hábitos e rotinas, das formas de agir. A liquidez da vida e a da sociedade se alimentam e se revigoram mutuamente. A vida líquida, assim como a sociedade líquidomoderna, não pode manter a forma ou permanecer em seu curso por muito tempo.

Numa sociedade líquido-moderna, as realizações individuais não podem solidificar-se em posses permanentes porque, em um piscar de olhos, os ativos se transformam em passivos, e as capacidades, em incapacidades. As condições de ação e as estratégias de reação envelhecem rapidamente e se 
tornam obsoletas antes de os atores terem uma chance de aprendê-las efetivamente.

Com o advento da cibercultura os tempos de trabalho, lazer, estudos podem ser configurados como uma sucessão de espaços, nos quais nós interferimos e estes também nos afetam. Hoje quando falamos em mobilidade fica clara a ideia de espaços que percorremos na sucessão de tempos. A extensão geográfica se faz e se refaz constantemente no contexto midiático (acesso/transmissão/recepção), numa fugacidade avassaladora. É uma existência dupla e concomitante, na rede e fora dela. Estamos dentro e fora de casa ao mesmo tempo, ou seja, nos encontramos em um espaço coletivo, todavia estamos em nossa redoma protetora do lar, do escritório, do automóvel, do shopping. Nesses casos, a diferença entre público e privado fica praticamente abolida. Tudo pode ser acessado de qualquer lugar a qualquer momento. Ainda para Bauman (2009, p. 10)

As chances mais amplas de vitória pertencem às pessoas que circulam perto do topo da pirâmide do poder global, para as quais o espaço pouco significa e a distância não é problema. Pessoas que se consideram em casa em muitos lugares, mas em nenhum deles em particular. Tão leves, lépidas e voláteis quanto o comércio e as finanças cada vez mais globais e extraterritoriais que as assistiram no parto e que sustentam sua existência de nômades. Como as descreveu Jacques Attali, "elas não possuem fábricas, terras, nem ocupam posições administrativas. Sua riqueza vem de um bem portátil: o conhecimento das leis do labirinto." Elas "adoram criar, jogar e manter-se em movimento". Vivem em uma sociedade "de valores voláteis, descuidada do futuro, egoísta e hedonista". Veem "as novidades como inovações, a precariedade como um valor, a instabilidade como imperativo, o hibridismo como riqueza". Em graus variados, todas essas pessoas dominam e praticam a arte da "vida líquida": aquiescência à desorientação, imunidade à vertigem, adaptação ao estado de tontura, tolerância com a falta de itinerário e direção, e com a duração indefinida da viagem.

O conceito de cidade é insuficiente para dar conta da glocalização da existência, pois ao articular telegeograficamente as culturas acaba também por moldá-las. O conceito de civilização midiática, glocal ou glocalizada, por sua vez, diz respeito a um modelo que depende dos meios - de massa e telemáticos - e encerra em seu perfil, um enorme processo midiático e ao mesmo tempo em que habita as cidades está fora delas. O processo de glocalização coloca o contexto glocal na cultura e assim rearranja o espaço geográfico, ao vinculá-lo com o global. Esse rearranjo traz mais uma característica dessa nova sociedade; o contexto glocal se transforma num bunker.

A bunkerização glocal da existência é o arranjo espaço-temporal da atualidade e, ao contrário do original, o bunker glocal não é exclusivamente material, palpável, não é uma espacialização visível. Na civilização midiática atual o bunker representa a infraestrutura 
tecnológica do ambiente que, muitas vezes, estão fixados de forma a rodear o sujeito, normalmente ao alcance de suas mãos, na ponta de seus dedos.

\section{Fanfiction}

A leitura de modo geral amplia e diversifica as visões e interpretações sobre o mundo e da vida como um todo. É preciso estar atento a esta questão, pois a ausência da leitura na vida bloqueia a possibilidade de pleno exercício de cidadania e acaba, de certa forma, excluindo dos acontecimentos, da interpretação, da imaginação e da ficção arquitetada pelo autor, seja em romances ou artigos; crônicas contos, poesias ou manifestos, jornais ou ensaios, gibis ou histórias infantil ou infanto-juvenil, enfim, são inúmeras as possibilidades de mergulhar no mundo da fantasia e da realidade encontradas no mundo das palavras.

Portanto, é de suma importância desenvolver em nós uma "cultura de leitura", pois só assim haverá aprendizes e formadores de opinião em todo ambiente social e democrático.

Programa Internacional de Avaliação de Estudantes (O PISA) da Organização para Cooperação e Desenvolvimento Econômico (OECD) foi criado para medir a capacitação dos jovens que estão prestes a concluir a escolaridade compulsória para enfrentar os desafios das sociedades atuais, dependentes de conhecimentos, enfocando habilidades de reflexão, de aplicação de conhecimentos e enfrentamento de desafios.

Segundo autores citados no PISA (2000), um fator importante que permite prever a compreensão em leitura é a quantidade de tempo que os estudantes gastam lendo. Se os estudantes leem bem, tendem a ler mais e, consequentemente, adquirem mais conhecimentos em todos os domínios. Estudantes que têm hábitos deficientes de leitura frequentemente acham que o material de leitura é difícil demais, portanto, desenvolvem uma atitude negativa em relação à leitura, acabam entrando em um círculo vicioso, uma vez que, por lerem menos, têm menos oportunidade de desenvolver estratégias de compreensão da leitura, e, dessa forma, ficam defasados em todas as disciplinas, já que a leitura é necessária para todas as áreas acadêmicas.

Na tentativa de simular situações autênticas de leitura, a avaliação de leitura do PISA (2000) mede os cinco seguintes aspectos associados à compreensão integral de um texto, seja este contínuo ou não-contínuo: construir uma compreensão geral ampla, recuperar informações, desenvolver uma interpretação, refletir sobre o conteúdo e forma de um texto e avaliá-los.

Em relação aos níveis de proficiência no letramento em leitura, foi registrado que, em parte, as dificuldades são determinadas pela extensão, pela estrutura e pela complexidade do 
próprio texto. No entanto, notaram também que, na maioria das unidades de leitura, as questões ou instruções variam ao longo da escala de letramento em leitura. Isso significa que, embora a estrutura de um texto contribua para a dificuldade de um item, o que o leitor precisa fazer com o texto, definido pela questão ou instrução, afeta a dificuldade total da tarefa (PISA, 2000).

Recentemente, alguns trabalhos voltam-se às práticas sociais de leitura ligadas a determinadas comunidades de leitores: leitura feminina de romances sentimentais de massa, como as leitoras da série Sabrina, leitores de Role Plaing Games (RPG), leitores de assentamentos, leitores universitários.

Fenômenos de leitura, no entanto, não são abordados em pesquisas por se tratarem de ocorrências efêmeras. Porém, por trás destes fenômenos ocasionais parece haver uma raiz que libera de tempos em tempos caules diferenciados, mas que se alimentam da mesma fonte.

Nesse contexto, insere-se a fanfiction. Não como uma nova forma de leitura/ escrita, uma vez que esta já era praticada desde 1920 sob outras formas.

Para o propósito deste estudo a fanfiction é entendida como uma apropriação do conteúdo midiático realizado pelos ciberjovens. Não se pretende criar uma definição para o termo ou mesmo promover uma discussão entre as definições já criadas e apresentadas na literatura. Pode-se, para efeito deste, trabalhar com a ideia de fanfictions dividindo o vocábulo para promover sua melhor compreensão deixando: fictions sendo compreendida como ficções, um gênero literário extremamente difundido e; fan sendo compreendido como fã, ou um pouco mais forte, fanático.

Admiradores de obras de ficção que se envolveram tanto com tais obras a ponto de desenvolverem a necessidade de interagir com estas elaborando um mecanismo para tal interação. Apropriar o contexto, personagens, o próprio enredo e ir além, dando seu ponto de vista, seu toque, sua direção.

Fãs que ao se apropriarem da obra, reescrevem e recriam esta obra, como num universo paralelo que existisse variadas possibilidades para o desenvolvimento de uma mesma obra de ficção.

Estes fãs /fanáticos não se contentando em apenas consumir o conteúdo produzido pela mídia com seus heróis e anti-heróis. Assumem o protagonismo das telas e escrevem suas próprias construções textuais.

São fãs escrevendo diferentes gêneros textuais com seus ídolos estrelando tais produções. Uma recriação cultural. 
Na fanfiction não há interesse pelas credenciais do autor. No caso das fanfictions postadas em aplicativos disponíveis em dispositivos móveis como smartphones, as curtidas darão ou não o tom do texto. Nem mesmo a preocupação com estas é algo escravizador para o leitor/ escritor.

Linhas, parágrafos ou capítulos inteiros são escritos pelo único e maravilhoso desejo do leitor escritor. Eles florescem de sua necessidade, sua não conformidade com os rumos da obra de que é fã / fanático e seu desejo de se expressar.

Se, e somente se, em universos paralelos Capitu provasse sua inocência a Bentinho? Espere, mas e se Capitu fosse flagrada em sua traição a Bentinho com seu vizinho e não seu melhor amigo? E se tantos fãs de Machado de Assis, tantos críticos e leitores que já debateram a suposta relação entre Bentinho e Capitu o fizessem nesse universo paralelo, o virtual, por meio de fanfictions?

Assim como a leitura se diversifica, o leitor também ${ }^{4}$. O que este projeto propõe é um olhar sobre as "comunidades de leitores/ escritores". Leitores / escritores que se unem por um objeto de desejo em comum, por uma espécie singular de leitura, definida por diferentes critérios e níveis.

\section{Metodologia}

O caminho escolhido foi o da observação durante três meses de um app disponível gratuitamente numa loja virtual de aplicativos (play store do google), que funciona em sistema android.

Spirit fanfics foi o aplicativo escolhido. Este aplicativo possui página na internet e funcionou na primeira década de 2000 oferecendo espaço para leitura, escrita, postagens, comentários e curtidas.

Atualmente ele também funciona em ambiente android em dispositivos móveis, sendo que nestes não há a exigência de estar on-line. Pode-se fazer o download de uma história e acessar no momento e local mais convenientes.

\footnotetext{
${ }^{4}$ Seja por faixa etária, grau de escolaridade, interesses variados etc.
} 


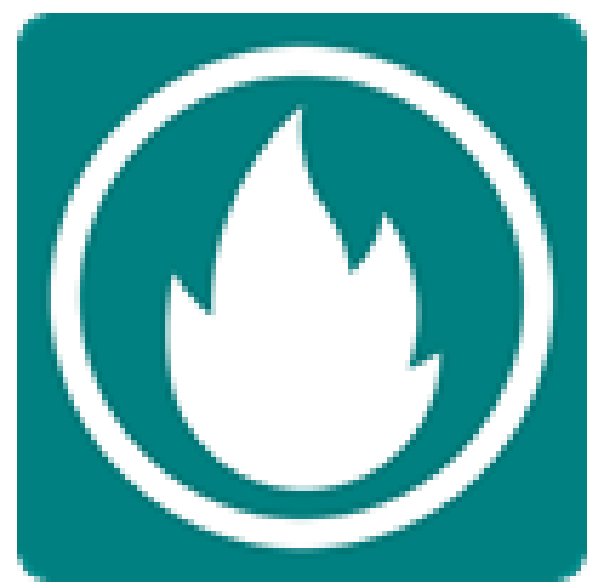

Figura 1 - Logo do App Spirit fanfics.

Fonte: site Baixaki

Tal app possui 13 categorias, 58 gêneros e 40 tags.

No perfil do usuário é possível identificar os seguintes itens:

Descobrir - indica categorias, recomendadas, recentes, destaques, gêneros, tags;

Atividades / Timeline - mostra mensagens, atividades e menções;

Biblioteca - indica leituras atuais, arquivadas, listas de leitura;

Favoritos - indica histórias marcadas como favoritas;

Minhas histórias - minhas histórias (indica se o usuário postou alguma história) e histórias excluídas;

Mensagens - aqui há caixa de entrada, enviadas e lixeira;

\section{Histórico}

Configurações - Aqui entre outros é possível ler o "sobre". Onde encontra-se: avaliar, suporte, licenças de código aberto, regras de envio, termos de uso, política de privacidade, versão.

Tabela 1 - Informações extraídas do app sobre cada história

\section{EM CADA HISTÓRIA É POSSÍVEL ENCONTRAR AS SEGUINTES INFORMAÇÕES}

\begin{tabular}{|l|l|}
\hline INICIADO EM & LISTAS DE LEITURA \\
\hline ATUALIZADO EM & PALAVRAS \\
\hline CLASSIFICAÇÃO (IDADE) & TERMINADA SIM OU NAO \\
\hline IDIOMA & AVISO LEGAL \\
\hline VIZUALIZAÇÃO (No) & CATEGORIAS (13) \\
\hline
\end{tabular}


FAVORITOS

COMENTÁRIOS (No)

GÊNEROS (58)
AVISOS

PERSONAGENS

TAGS (40)

\section{LISTAS DE CAPÍTULOS}

Fonte: SILVA, 2017

Nessa imensa plataforma há vários autores e " $n$ " histórias sendo escritas ou já terminadas.

Não há um comprometimento com extensão, e o ritmo da escrita parece em muito contar com a colaboração das curtidas dos leitores.

Há histórias em andamento com quatro, catorze, trinta e três e até setenta e dois capítulos.

Semanalmente são emitidas notificações aos cadastrados no app, lembrando de que novas histórias foram postadas e incentivando a leitura.

O marketing do app é também um marketing sobre a cultura da leitura.

Segundo o site Baixaki (2017):

Se você é fã de fanfics e gostaria de ter acesso a um grande acervo dessas histórias fictícias, o Spirit Fanfics é o lugar certo para encontra-las. Através desse serviço, você tem acesso a milhares de contos dos mais diversos temas, gêneros e histórias. Todos, é claro, vêm para explorar possibilidades das mais variadas para seus personagens, celebridades e séries favoritas.

Usar esse serviço é uma tarefa extremamente simples. Através do app, você pode desde buscar histórias por tema, tag ou uma pesquisa personalizada até simplesmente acompanhar o conteúdo de acordo com os lançamentos mais recentes ou os principais destaques na página.

Usar o site para criar e publicar suas próprias fanfics é uma possibilidade, é claro. Para isso, simplesmente clique no botão laranja "+" e faça o envio de seu texto lembrando de seguir as regras de publicação do Spirit Fanfics, obviamente. 


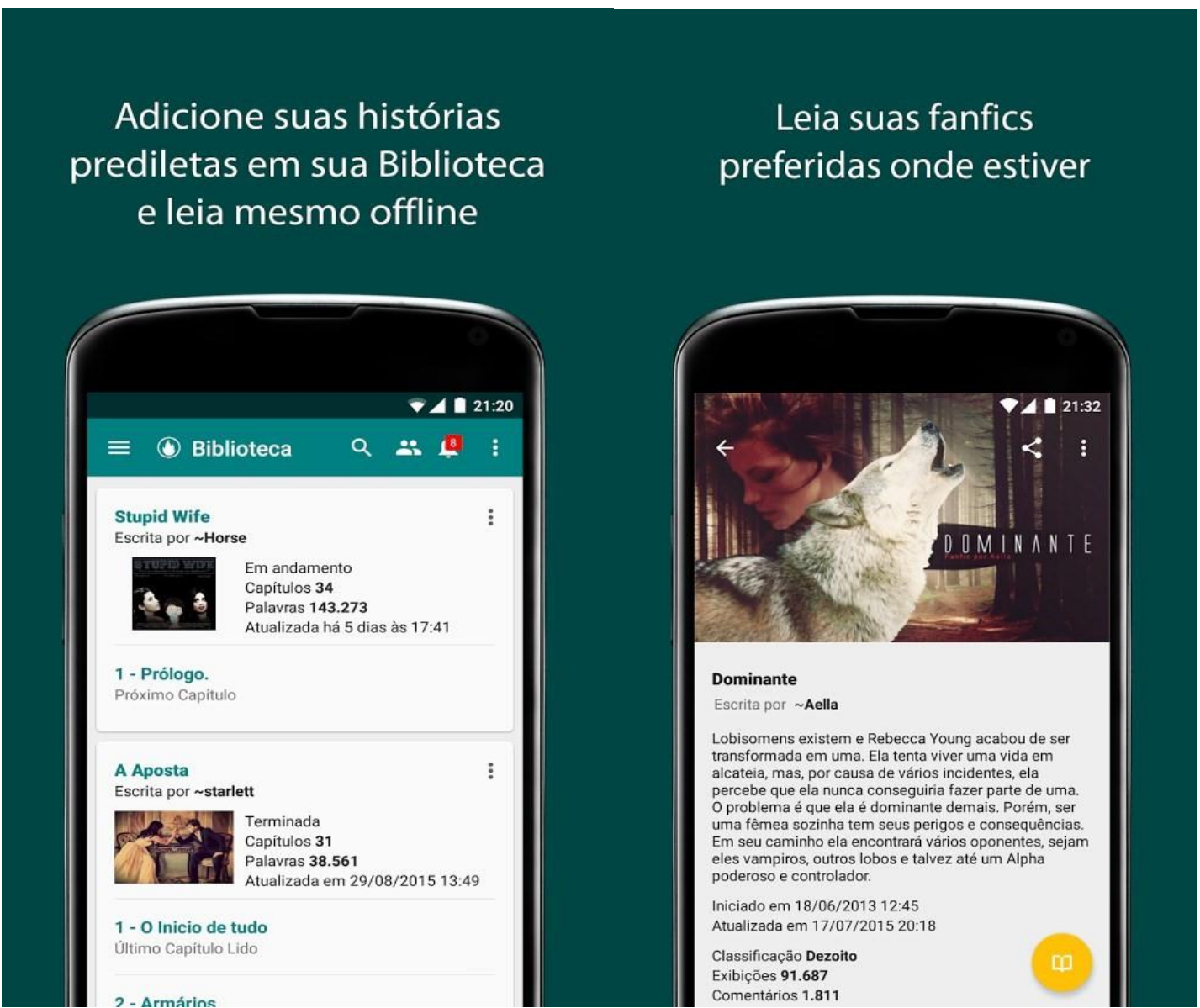

Figura 2 - Prints de divulgação do App Spirit fanfics.

Fonte: site Baixaki

O app ainda conta com um setor muito curioso, cujo objetivo é colaborar para que os jovens escritores aprimorem seu talento. É o chamado: Aprendendo a ser um mestre escritor

Neste tópico o app dialoga com os usuários nos seguintes termos:

Como ninguém nasce sabendo escrever obras-primas de primeira, Spirit Fanfics também conta com uma série de ferramentas que ajudam você em todo o processo de criar suas obras - do conhecimento básico para escrever até a publicação de sua obra.

Para aqueles que precisam de algumas aulinhas de português, por exemplo, tudo o que você precisa fazer é acessar a área "aulas" do serviço. Aqui é possível encontrar dezenas de informações importantes sobre a língua portuguesa, indo desde regras básicas até itens mais avançados e dicas para ajudá-lo a melhorar sua escrita.

Já para ajudá-lo a saber se sua história está boa, a dica é ir até a área "Beta Readers". Como o nome indica, aqui você encontra diversos leitores dispostos a avaliar sua obra para que consiga encontrar falhas e melhorar seu trabalho; tudo é uma questão de achar alguém que se encaixe no seu tipo de texto.

Como se isso não fosse suficiente, até mesmo as capas de suas obras podem ser feitas pelo Spirit Fanfics através da seção "Capistas".

\section{Análise das observações}


A cultura do ciberespaço é fluida. Não demonstra necessariamente uma preocupação com a reprodução massificada ou disseminação. Mas postar sua marca no espaço virtual.

O que leitores/escritores demonstraram ao longo desses meses de observação foi em geral um domínio e absorção do conteúdo sobre o qual se dispunham a escrever. Um mergulho profundo em determinado assunto. Não uma simples assimilação, mas um posicionamento. Uma marca diante do objeto.

Mesmo que imbuídos de mascaras que os transfiguram no virtual, na liquidez do espaço virtual, suas pegadas são firmes.

Não há uma preocupação com o autor como o conhecemos. Aqui nome e sobrenome não querem dizer muito. Os escritores usam em sua esmagadora maioria pseudônimos. A vaidade da autoria parece não contaminar.

Ao contrário dos youtubers que vivem de sua notoriedade e do número de curtidas e visualizações, esses jovens marcam com um estilo, um tema, uma abordagem que conquista o leitor. Visibilidade não é fundamental. Não é um espetáculo. Talvez mais um diálogo ou até uma terapia ou confissão sussurrada nos bits do espaço virtual.

Eles não se rendem ao mercado editorial. A escrita é algo que lhes pertence. Se há ou não o leitor ideal é outra questão. Há, sim, o espaço ideal para deixarem suas ideias, suas mensagens, traumas, esperanças, inquietações tão próprias dos escritores.

E quanto a originalidade da obra? Bem, até que ponto tudo já não foi escrito ou é fruto do que já lemos? As histórias são honestamente baseadas em outras. A originalidade está na declaração de que "esta obra se baseia na obra X".

Nem sempre há o uso do padrão culto da língua, mas é realmente essencial tal uso ou o essencial é a efetivação da comunicação? E neste caso uma comunicação em rede, proporcionada por dispositivos móveis de uso extremamente democrático.

A usabilidade do aplicativo pode ser melhor testada, mas a princípio é de fácil manipulação e visualização. O fato de permitir o download de histórias para leitura off-line é um dos pontos positivos.

No Spirit fanfics são encontrados jovens que se apropriam da cultura letrada. E recriam sua escrita. No ritmo e formato que lhes interessa e convém.

São demonstrações de apropriação da cultura. São jovens que leem. São jovens que escrevem. Mas não nos moldes da escola ou da sociedade. Não da escola como esta se propõe a eles. Não no ritmo que a sociedade deseja deles. Não da forma que se espera deles. É a resposta às vezes tranquila, outras, rebelde, mas a demonstração de resistência e mais ainda existência. 


\section{Considerações finais}

Em tempos de tantas incertezas como buscar conclusões em um trabalho que se propôs desde sua introdução a provocações?

Nessa linha de raciocínio é importante ressaltar que a cultura teve e sempre terá uma importância gigantesca em nossa vida, em sua nova configuração ela não é apenas 'compatível' com a sociedade capitalista, mas parece ter praticamente tomado conta da sociedade.

A possibilidade de acesso e apropriação subjetiva de praticamente a totalidade da riqueza cultural produzida pela humanidade ao longo dos séculos é absolutamente inédita na história da civilização.

Trata-se de uma nova e grande biblioteca virtual e mundial de acesso "livre" a "qualquer" cidadão do planeta. O acesso ao conhecimento e à cultura os quais antes da tecnologia digital se encontravam apenas nos grandes centros urbanos, estão ou estarão a partir de agora disponíveis a todos independentemente do lugar aonde moram.

Os dispositivos móveis instauraram um novo nível de acesso. Todo um novo modo de produzir, registrar, distribuir e consumir bens culturais está sendo instituído no interior da hipermídia.

As fanfictions disponíveis em app em dispositivos móveis são uma realidade e uma possibilidade de leitura e escrita por jovens.

Ao escreverem, esses jovens provam que leem, comprovam um domínio sobre determinado assunto obtido através da leitura.

A leitura e a escrita são apropriadas pelos jovens que se utilizam de novas formas de manifestação cultural.

A fanfiction não exige um mercado editor e outras burocracias que os jovens dispensam e que acabam tornando a leitura algo monótono. Ao utilizarem dispositivos móveis eles a carregam consigo onde estiverem, on-line ou não. E estão cada vez mais abarrotados de informações.

Mas de que adiantará toda uma explosão de informações, todo um acúmulo de conhecimento, enquanto a humanidade não possuir os instrumentos necessários, a experiência e a prática de como manipulá-los a seu favor?

Existe uma série de condições que podem facilitar ou não o desenvolvimento do conhecimento. A criação e a manutenção de condições favoráveis ao desenvolvimento de um conhecimento contextualizado numa era pós-moderna, de pluralidade, democratização, 
globalização, mas principalmente de uma sociedade da informação ou do conhecimento na qual o status do conhecimento vem sendo gradualmente alterado é fundamental.

Faz-se necessário repensar o conceito de leitura, rever as pesquisas sobre leitura e aprofundar sobre os atuais meios e objetos de leitura da sociedade contemporânea. Quais têm sido as perguntas direcionadas aos leitores em potencial? 


\section{Referências}

BAUMAN, Zygmunt. Vida líquida. Rio de Janeiro: Zahar, 2009.

Globalização: as consequências humanas. Rio de Janeiro: Zahar,

1999.

Tempos líquidos. Rio de Janeiro: Zahar, 2007.

CANCLINI, Néstor García. Consumidores e cidadãos: conflitos multiculturais da globalização. Rio de Janeiro: UFRJ, 2005.

CANCLINI, Néstor Garcia. Culturas híbridas: estratégias para entrar e sair da modernidade. São Paulo: Edusp, 2013

CASTELLS, Manuel. O poder da identidade. Rio de Janeiro: Paz e Terra, 1999.

GIDDENS, Anthony. As consequências da modernidade. São Paulo: Unesp. 2002.

HALL, Stuart. A identidade cultural na pós-modernidade. Rio de Janeiro: DP\&A, 2003.

HARVEY, David. Condição pós-moderna. São Paulo: Loyola, 1989.

IANNI, Octávio. Os enigmas da modernidade-mundo. Cidade: Civilização Brasileira, 2003.

LEVY, Pierre. Cibercultura. São Paulo: Ed. 34, 1999.

LEVY, Pierre. O que é virtual. São Paulo: Ed. 34, 2009

LYOTARD, Jean-François. A condição pós-moderna. Rio de Janeiro: José Olympo, 2011.

MEC PISA 2000: relatório final. Brasília, dez, 2001. Disponível em:

http://www.inep.gov.br/enem/pisa. Acesso em: 20 de março de 2009.

Portal do site Baixaki. Disponível em: http://www.baixaki.com.br. Acesso em 28 de maio de 2017.

SANTOS, Milton. Por outra globalização. Rio de Janeiro: Record, 2001.

SANTOS, Boaventura de Sousa. Contra o desperdício da experiência: a pedagogia do conflito. Porto Alegre: Redes editoras, 2009.

SODRE, Muniz. Antropológica do espelho: uma teoria da comunicação linear e em rede. Petrópolis: Vozes, 2011. 